BNL-113970-2017-JA

\title{
Investigation of Thermal Stability of P2-NaxCoO2 Cathode Materials for Sodium Ion Batteries Using Real-Time Electron Microscopy
}

S. Hwang, Y. Lee, E. Jo, K. Y. Chung, W. Choi, S. M. Kim, and W. Chang

Accepted by the ACS Applied Materials \& Interfaces

May 2017

Center for Functional Nanomaterials

Brookhaven National Laboratory

\author{
U.S. Department of Energy \\ USDOE Office of Science (SC), \\ Basic Energy Sciences (BES) (SC-22)
}

Notice: This manuscript has been authored by employees of Brookhaven Science Associates, LLC under Contract No. DE-SC0012704 with the U.S. Department of Energy. The publisher by accepting the manuscript for publication acknowledges that the United States Government retains a non-exclusive, paid-up, irrevocable, world-wide license to publish or reproduce the published form of this manuscript, or allow others to do so, for United States Government purposes. 


\section{DISCLAIMER}

This report was prepared as an account of work sponsored by an agency of the United States Government. Neither the United States Government nor any agency thereof, nor any of their employees, nor any of their contractors, subcontractors, or their employees, makes any warranty, express or implied, or assumes any legal liability or responsibility for the accuracy, completeness, or any third party's use or the results of such use of any information, apparatus, product, or process disclosed, or represents that its use would not infringe privately owned rights. Reference herein to any specific commercial product, process, or service by trade name, trademark, manufacturer, or otherwise, does not necessarily constitute or imply its endorsement, recommendation, or favoring by the United States Government or any agency thereof or its contractors or subcontractors. The views and opinions of authors expressed herein do not necessarily state or reflect those of the United States Government or any agency thereof. 


\section{Investigation of Thermal Stability of $\mathbf{P 2}-\mathrm{Na}_{\mathbf{x}} \mathrm{CoO}_{2}$ Cathode Materials}

\section{2 for Sodium Ion Batteries using Real-Time Electron Microscopy}

4 Sooyeon Hwang ${ }^{1 \#}$, Yongho Lee ${ }^{1}$, Eunmi Jo ${ }^{l}$, Kyung Yoon Chung ${ }^{1}$, Wonchang Choi ${ }^{1, *}$,

5 Seung Min Kim ${ }^{2, *}$, Wonyoung Chang ${ }^{1, *}$

$6{ }^{1}$ Center for Energy Convergence, Korea Institute of Science and Technology (KIST),

$7 \quad$ Seoul 02792, Republic of Korea

$8{ }^{2}$ Carbon Composite Materials Research Centre, Institute of Advanced Composite

9 Materials, KIST, Wanju-gun 55324, Republic of Korea

10 "Present address: Center for Functional Nanomaterials, Brookhaven National Laboratory,

11 Upton, New York 11973, United States

12

13 *Corresponding authors: W. Choi (wonchangchoi@kist.re.kr) $\quad$ S. $\quad$ M. Kim

14 (seungmin.kim@kist.re.kr) and W. Chang (wy@kist.re.kr)

16 Keywords: sodium ion batteries, cathode materials, thermal stability, $\mathrm{NaCoO}_{2}$,

17 transmission electron microscopy, in-situ heating 


\section{Abstract}

2 Here, we take advantage of in-situ transmission electron microscopy (TEM) to

3 investigate the thermal stability of P2-type $\mathrm{Na}_{\mathrm{x}} \mathrm{CoO}_{2}$ cathode materials for sodium ion

4 batteries, which are promising candidates for next-generation lithium ion batteries. A

5 double-tilt TEM heating holder was used to directly characterize the changes in the

6 morphology and the crystallographic and electronic structures of the materials with

7 increase in temperature. The electron diffraction pattern and the electron energy loss

8 spectra demonstrated the presence of cobalt oxides $\left(\mathrm{Co}_{3} \mathrm{O}_{4}, \mathrm{CoO}\right)$ and even metallic

9 cobalt (Co) at higher temperatures as a result of reduction of Co ions and loss of oxygen.

10 The bright-field TEM images revealed that the surface of $\mathrm{Na}_{\mathrm{x}} \mathrm{CoO}_{2}$ becomes porous at

11 high temperatures. Higher cutoff voltages result in degrading thermal stability of

$12 \mathrm{Na}_{\mathrm{x}} \mathrm{CoO}_{2}$. The observations herein provide a valuable insight that thermal stability is one

13 of the important factors to be considered in addition to the electrochemical properties

14 when developing new electrode materials for novel battery systems. 


\section{Introduction}

2 Despite the huge success of lithium ion batteries (LIBs), alternate power sources

3 are in great demand because of the limited resources of lithium.. ${ }^{1}$ Interests on replacing

$4 \mathrm{Li}$ by more abundant element of $\mathrm{Na}, \mathrm{Mg}$ or $\mathrm{Ca}$ grow significantly from the viewpoint of

5 sustainability. Among them, sodium ion batteries (SIBs) are the most promising

6 candidates for replacing the LIB technology. $\mathrm{Na}$ is one of the abundant elements on

7 earth. $^{2}$ In addition, both $\mathrm{Li}$ and $\mathrm{Na}$ are alkali metals; thus, they have similar chemical

8 properties. Since the fundamental mechanisms of LIB can also be applied for SIB, we can

9 take advantage of the well-established LIB technology to develop and improve the SIB

10 technology. Owing to these virtues, SIBs have attracted increasing attention for large-

11 scale energy storage applications.

12 Sodium transition metal oxides $\left(\mathrm{Na}_{\mathrm{x}} \mathrm{TMO}_{2}\right)$ are the most widely investigated

13 cathode materials for $\mathrm{SIBs},{ }^{3-6}$ because lithium transition metal oxides $\left(\mathrm{LiTMO}_{2}\right)$,

14 representatively $\mathrm{LiCoO}_{2}$, are well-understood systems and have been utilized successfully

15 for practical applications. While $\mathrm{Li}$ ions take octahedral sites in $\mathrm{LiTMO}_{2}, \mathrm{Na}$ ions can

16 occupy either octahedral or prismatic sites, resulting in various kinds of oxygen stacking.

17 For example, $\mathrm{Na}_{\mathrm{x}} \mathrm{CoO}_{2}$ has $\mathrm{O} 3, \mathrm{P} 2$, and $\mathrm{P} 3$ structures depending on the Na content, where

$18 \mathrm{O}$ and $\mathrm{P}$ indicate $\mathrm{Na}$ ions occupying the octahedral and prismatic sites, respectively. ${ }^{7,8}$

19 Among these structures, the P2 structure is favored because of its higher energy density

20 and longer cycle life. ${ }^{6,9}$ Oxygen stacking in the P2 structure is ABBA while that in the O3

21 structure, adopted by $\mathrm{LiTMO}_{2}$, is $\mathrm{ABCABC}$. These inherent dissimilarities in the crystal

22 structures might induce different types of structural changes in $\mathrm{Na}_{\mathrm{x}} \mathrm{TMO}_{2}$ compared to

23 the well-known $\mathrm{LiTMO}_{2}$ systems under various conditions. Therefore, these changes 
1 should be carefully considered because the structural properties of electrode materials are

2 strongly correlated with the intercalation capability and the stability of the batteries.

Previous studies on $\mathrm{LiTMO}_{2}$ have demonstrated that the structure of $\mathrm{LiTMO}_{2}$ can

4 be modified during charge/discharge or with increase in the temperature. ${ }^{10-13}$ Structural

5 changes of $\mathrm{LiTMO}_{2}$ at high temperatures are accompanied with oxygen evolution ${ }^{11}$ which

6 makes the whole battery system extremely dangerous due to reaction with flammable

7 electrolytes. The thermal stability of $\mathrm{Na}_{x} \mathrm{TMO}_{2}$ has been investigated using a variety of

8 techniques such as, accelerating rate calorimetry, ${ }^{5,14}$ differential scanning calorimetry, ${ }^{15}$

9 and time-resolved X-ray diffraction ${ }^{16}$; however, issues related to thermal safety have not

10 been fully assessed. ${ }^{17}$ Especially, consideration of local structural changes are lacking in

11 previously reported studies even though local surface areas are subjected to deeper de-

12 intercalation ${ }^{18}$ and more violent thermal decomposition. ${ }^{11,12}$

13 In the present work, we investigated the local changes in crystallographic and

14 electronic structures as well as morphologies of charged $\mathrm{P} 2-\mathrm{Na}_{\mathrm{x}} \mathrm{CoO}_{2}$ with increase in

15 temperature using real-time electron microcopy. The material $\mathrm{P} 2-\mathrm{Na}_{\mathrm{x}} \mathrm{CoO}_{2}$ was selected

16 as a model system of $\mathrm{Na}_{\mathrm{x}} \mathrm{TMO}_{2}$ because of its chemical similarity with $\mathrm{LiCoO}_{2}$, the most

17 popular cathode material for LIBs, and the superior electrochemical properties of P2-

18 structured $\mathrm{Na}_{\mathrm{x}} \mathrm{TMO}_{2}$ cathode materials. ${ }^{6,9}$ The surface areas of cathode materials are of

19 particular interest since the local surface area experiences harsher conditions than the

20 bulk due to the over-potential developed at the interface between the cathode material

21 and the electrolyte. Using electron microscopy, we can observe the development of

22 porosity with modifications in the crystallographic and electronic structures while heating

$23 \mathrm{P} 2-\mathrm{Na}_{\mathrm{x}} \mathrm{CoO}_{2}$ after initial charging. As the temperature increases, desodiated $\mathrm{Na}_{\mathrm{x}} \mathrm{CoO}_{2}$ 
1 decomposes into cobalt oxides and even into metallic Co. As most of the $\mathrm{Na}$ ions are

2 extracted from the structure, $\mathrm{Na}_{\mathrm{x}} \mathrm{CoO}_{2}$ becomes thermally unstable, resulting in thermal

3 decomposition at lower temperatures. This study presents the possible safety threats of

$4 \quad \mathrm{P} 2-\mathrm{Na}_{\mathrm{x}} \mathrm{TMO}_{2}$, which should be overcome for practical applications.

5

6 Experimental Details

7

8 Synthesis: $\mathrm{P} 2-\mathrm{Na}_{\mathrm{x}} \mathrm{CoO}_{2}$ (NCO) raw material was synthesized by solid-state reaction.

9 Stoichiometric amounts of sodium carbonate $\left(\mathrm{Na}_{2} \mathrm{CO}_{3}\right)$ and cobalt oxide $\left(\mathrm{Co}_{3} \mathrm{O}_{4}\right)$ were

10 well ground using a mortar and pestle, and then, the mixtures were pelletized, followed

11 by heat treatment at $850{ }^{\circ} \mathrm{C}$ for $24 \mathrm{~h}$ under air flow. The weight percent of $\mathrm{Na}$ and $\mathrm{Co}$ of

12 the as-synthesized material was determined using an atomic absorption spectrometer

13 (ICE 3000 series, Thermos). The bulk crystal structure of NCO was investigated by X-

14 ray diffraction (XRD) which was performed with a D-max 2500/PC X-ray diffractometer

15 (Rigaku) using $\mathrm{Cu} \mathrm{K \alpha}$ radiation over a $2 \theta$ range of $10-70^{\circ}$ at a scan rate of $2 \% \mathrm{~min}$.

16 Electrochemical tests: The NCO cathode materials were electrochemically charged at a

17 rate of $10 \mathrm{~mA} / \mathrm{g}$ at constant current condition until the cell potential reached 3.5, 4.1, and

$184.3 \mathrm{~V}$. The cathode part was prepared from the slurry of $80 \mathrm{wt} . \%$ of active material

19 (NCO), $10 \mathrm{wt} . \%$ of conducting carbon (Super P), and $10 \mathrm{wt} . \%$ of polyvinylidene fluoride

20 binder in N-methyl pyrrolidone solvent. This slurry was then coated onto an Al foil,

21 which acted as a current collector. A 2032 type coin cell was assembled using the

22 prepared cathode part, Na metal as the anode, a glass fiber filter (GF/F, Whatman) as the

23 separator, and an electrolyte of $1 \mathrm{M} \mathrm{NaClO}_{4}$ dissolved in a solvent of ethylene carbonate,

24 diethyl carbonate, and propylene carbonate (1:1:1 by volume). 
1 Sample preparation: After attaining the required cutoff voltages $(3.5,4.1$, and $4.3 \mathrm{~V})$,

2 the coin cells were disassembled, and the cathode was cleaned with pure dimethyl

3 carbonate (DMC) solution to remove the residual salts. The charged NCO particles were

4 acquired by abrading the $\mathrm{Al}$ foil. The powder samples were dispersed in pure DMC

5 solvent before dropping onto a lacey carbon TEM grid. All the sample preparation

6 processes were carried out in an argon-filled glove box to minimize the exposure of the

$7 \quad$ sample to air and moisture.

8 In-situ TEM experiments: The changes in the structures of the NCO cathode materials

9 during heating were observed in real time using Tecnai $\mathrm{G}^{2}$ F20 (FEI) TEM at an

10 accelerating voltage of $120 \mathrm{kV}$. A 652 double-tilt heating holder (Gatan) was utilized for

11 increasing the temperature from room temperature $\left(25^{\circ} \mathrm{C}\right)$ to $400{ }^{\circ} \mathrm{C}$. The electron

12 energy loss (EEL) spectra were acquired using a GIF Tridiem system (Gatan). The

13 energy resolution of the EEL spectrum, as determined by measuring the full-width at half

14 maximum of the zero-loss peak, was around $1 \mathrm{eV}$. The backgrounds of all the spectra

15 were subtracted using the power law method embedded in Digital Micrograph software

16 (Gatan).

\section{Results and Discussion}

18 Sodium cobalt oxide $\left(\mathrm{Na}_{\mathrm{x}} \mathrm{CoO}_{2}, \mathrm{NCO}\right)$ active cathode material was synthesized by

19 the solid-state method. The composition ' $\mathrm{x}$ ' was determined to be 0.69 by atomic

20 absorption spectroscopy (Table S1). The scanning electron microscopy (SEM) image

21 (Figure 1a) shows that the primary particles of the as-synthesized NCO material exhibit

22 plate-like morphologies. Figure $1 \mathrm{~b}$ shows the X-ray diffraction pattern of the pristine

$23 \mathrm{NCO}$ material, which matches that of $\mathrm{P} 2-\mathrm{Na}_{0.7} \mathrm{CoO}_{2}$ reference (JCPDS \#30-1182), 
1 demonstrating that the as-synthesized $\mathrm{NCO}$ has $\mathrm{P} 2$ structure. To investigate the thermal

2 stability of the NCO material depending on the remaining sodium content, we controlled

3 the cut-off voltages $(3.5,4.1$, and $4.3 \mathrm{~V})$. The charge profiles of the NCO cathode

4 material are shown in Figure 1c. The initial charge curve to $4.3 \mathrm{~V}$ shows multiple

5 plateaus at $2.7,2.95,3.3,3.6$, and $4.0 \mathrm{~V}$, indicating that the sodium de-intercalation

6 process undergoes complicated series of phase transitions. When charged from the initial

7 composition of $\mathrm{NCO}$ up to $3.5,4.1$, and $4.3 \mathrm{~V}$, the materials delivered a charge capacity

8 of $45.8,116.1$, and $146.8 \mathrm{mAh} / \mathrm{g}$, respectively, corresponding to the formation of

$9 \mathrm{Na}_{0.52} \mathrm{CoO}_{2}, \mathrm{Na}_{0.24} \mathrm{CoO}_{2}$, and $\mathrm{Na}_{0.12} \mathrm{CoO}_{2}$, assuming that all the electrons moving out from

10 the NCO cathode are compensated by the increase in the valence of Co with sodium de-

11 intercalation. After the initial charging with different cutoff voltages, the bulk crystal

12 structures of the NCO materials were examined by XRD (Figure 1d). Compared to the

13 XRD pattern of the pristine material, peak splitting, emerging, or disappearing was not

14 observed in the XRD patterns of the charged materials, indicating that the bulk structures

15 are well maintained after the initial charge. Meanwhile, diffraction peak shift is

16 observable and the changes in lattice parameters are summarized at Figure S1 in the

17 Supporting Information.

18 Changes in the morphologies of the $\mathrm{NCO}$ materials during heating were tracked

19 by recording a series of bright field images, as shown in Figure 2. As the temperature

20 increased, the surface areas of the NCO materials became porous, implying that gas

21 evolution has occurred. The morphologies of the NCO materials changed significantly

22 with increase in the cutoff voltages or decrease in the $\mathrm{Na}$ ions remaining in the original

23 structure. Figure S2 in the Supporting Information exhibits that morphological changes 
1 occurred at the whole NCO particles upon heating, which indicates that thermal

2 degradation initiates at the edge of the particles and propagates toward the bulk and the

3 degree of thermal decomposition becomes severer with depth of charge. The crystal

4 phases at each temperature were determined from the selected area electron diffraction

5 (SAED) patterns (Figure 3). Details regarding the indexing of the SAED patterns are

6 provided in Figure S3. At high temperatures, the surface of desodiated $\mathrm{Na}_{\mathrm{x}} \mathrm{CoO}_{2}$

7 decomposed into cobalt oxides $\left(\mathrm{Co}_{3} \mathrm{O}_{4}, \mathrm{CoO}\right)$ or even metallic $\mathrm{Co}$. The NCO cathode

8 materials charged to higher voltages became more thermally unstable, resulting in the

9 degradation of $\mathrm{NCO}$ at lower temperatures. For example, the $\mathrm{Co}_{3} \mathrm{O}_{4}$ phase was found

10 even at $100{ }^{\circ} \mathrm{C}$ in the case of the sample charged to $4.3 \mathrm{~V}$, whereas for the sample

11 charged to $3.5 \mathrm{~V}$, the thermal decomposition to $\mathrm{Co}_{3} \mathrm{O}_{4}$ was apparent only at $400{ }^{\circ} \mathrm{C}$.

12 Sodium ordering between $\mathrm{CoO}_{2}$ layers has been reported to take place at a certain sodium

13 content $\left(\mathrm{x}=0.5\right.$ in $\left.\mathrm{Na}_{\mathrm{x}} \mathrm{CoO}_{2}\right)$ and temperature range $(410 \sim 470 \mathrm{~K})$, resulting in additional

14 diffraction spots of a superstructure hexagonal phase with doubled cell parameters in $a b$

15 plane. ${ }^{19} \mathrm{We}$ observed this superstructure in the samples charged at 4.1 and $4.3 \mathrm{~V}$ at

$16200{ }^{\circ} \mathrm{C}(473 \mathrm{~K})$. Faint diffraction spots from the superstructure were also observed in the

$173.5 \mathrm{~V}$-charged $\mathrm{NCO}$ at $300{ }^{\circ} \mathrm{C}$; we speculate that this sodium ordering is not fully relaxed

18 at temperatures higher than the previously reported temperature range.

19 The variations in the electronic structures of the NCO cathode materials during

20 heating were investigated by electron energy loss spectroscopy (EELS), which reflects

21 the density of states above the Fermi level. ${ }^{20}$ Electron microscopy allows us to investigate

22 the electronic and the crystallographic structures simultaneously, which is essential to

23 elucidate the direct relationship between thermal decomposition and chemistry of 
1 materials during heating. Figure 4 shows the $\mathrm{O}$ K-edge and the Co $\mathrm{L}_{2,3}$-edge EEL spectra

2 of the NCO cathode materials at different states of charging with increase in the

3 temperature. The intensity of each spectrum is normalized with the highest intensity of $\mathrm{O}$

$4 \mathrm{~K}$ - or $\mathrm{L}_{3}$-edge of $\mathrm{Co}_{2,3}$-edge. In the case of the $4.3 \mathrm{~V}$-charged sample, the $\mathrm{O} \mathrm{K}$-edge at

$5400{ }^{\circ} \mathrm{C}$ was exaggerated as a result of the intensity normalization. The raw EEL spectrum

6 is provided in Figure S4 in the supporting material, which shows that the O K-edge

7 almost vanished at $400{ }^{\circ} \mathrm{C}$. The $\mathrm{O}$ K-edge is mainly composed of two prominent peaks: a

8 pre-edge at $\sim 530 \mathrm{eV}$, which originates from the electron transition from $1 \mathrm{~s}$ to the

9 hybridized state of $\mathrm{O} 2 \mathrm{p}$ with localized $3 \mathrm{~d}$ of transition metal (TM, in this case Co), and

10 another above $540 \mathrm{eV}$, which is attributed to the electron transition to the hybridized state

11 of O $2 p$ with 4 sp of TM. ${ }^{10}$ The Co L-edge is derived from the transition from $2 p$ to the

12 highly localized $3 d$ state. Spin-orbit coupling splits the degeneracy of the $2 p$ state into

$132 p_{1 / 2}$ and $2 p_{3 / 2}$ levels, which results in two independent $L_{2}$ and $L_{3}$ edges. ${ }^{21}$ As the

14 temperature increases, both the O K- and the Co L-edges change: a positive shift in the

15 pre-edge of the $\mathrm{O} \mathrm{K}$-edge, a decrease in the onset energy of the $\mathrm{Co}_{2,3}$-edge, and changes

16 in the $\mathrm{L}_{3} / \mathrm{L}_{2}$ intensity ratio of Co. All these changes arise from the reduction of Co. ${ }^{10,21}$

17 The modifications in the electronic structures of the NCO materials upon heating

18 are presented in Figure 5. We utilized two indexes of $\Delta E$ and $\mathrm{L}_{3} / \mathrm{L}_{2}$ intensity ratio to

19 express the changes in $\mathrm{O} \mathrm{K}$ - and Co L-edges, respectively. The index $\Delta E$ corresponds to

20 the energy loss difference at the highest intensities of the pre-edge and the main peaks of

21 the $\mathrm{O}$ K-edge. As the Co ions binding with oxygen reduces, the pre-edge moves to higher

22 values of energy loss, resulting in a decrease in the $\Delta E \cdot{ }^{13}$ The threshold energy of the

$23 \mathrm{~L}_{2,3}$-edge and the $\mathrm{L}_{3} / \mathrm{L}_{2}$ intensity ratio reflect the oxidation state of the TM. However, we 
1 used the $\mathrm{L}_{3} / \mathrm{L}_{2}$ intensity ratio only for tracking the chemical state of Co because the

2 energy resolution of the electron beam $(\sim 1 \mathrm{eV})$ may lead to misinterpretation of the

3 chemical shift. As the temperature increases, the $\Delta E$ decreases while the $\mathrm{L}_{3} / \mathrm{L}_{2}$ intensity

4 ratio generally increases. In other words, reduction of Co occurs with increase in the

5 temperature, and the chemical state changes severely at lower temperatures for higher

6 cutoff voltages. The $4.3 \mathrm{~V}$-charged $\mathrm{NCO}$ additionally exhibited an unusual trend in the

$7 \quad \mathrm{~L}_{3} / \mathrm{L}_{2}$ ratio; it continuously increased until $300{ }^{\circ} \mathrm{C}$ and then decreased at $400{ }^{\circ} \mathrm{C}$. Figure

8 S4 shows that the $\mathrm{O}$ K-edge of the $4.3 \mathrm{~V}$-charged $\mathrm{NCO}$ at $400{ }^{\circ} \mathrm{C}$ almost disappears,

9 implying that most of the oxygen is released from the NCO materials in order to fulfill

10 the charge neutrality due to the reduction of Co. In the absence of oxygen, the Co ions are

11 ultimately reduced to the metallic state. The $\mathrm{L}_{3} / \mathrm{L}_{2}$ ratio of metallic Co is lower than that

12 of the ionized state. ${ }^{22}$ The $\mathrm{L}_{3} / \mathrm{L}_{2}$ ratios of different oxidation states of Co are shown in

13 Figure S5 and have been plotted based on reference 22. Therefore, the unusual decrease

14 in the $\mathrm{L}_{3} / \mathrm{L}_{2}$ ratio of the $4.3 \mathrm{~V}$-charged $\mathrm{NCO}$ at $400{ }^{\circ} \mathrm{C}$ originates from the ultimate

15 reduction of Co ion to metallic Co. All the changes in the electronic structures are well

16 matched to those in the crystallographic structures. The thermal decomposition from

$17 \mathrm{Na}_{\mathrm{x}} \mathrm{CoO}_{2}$ to $\mathrm{Co}_{3} \mathrm{O}_{4}, \mathrm{CoO}$, and eventually $\mathrm{Co}$ occurs with the continuous reduction of $\mathrm{Co}$

18 ions and the loss of oxygen, and the appearance of metallic Co was confirmed by both

19 SAED and EELS results.

20 Figure 6 summarizes schematically the changes occurred in charged NCO cathode

21 materials with a temperature range of room temperature to $400{ }^{\circ} \mathrm{C}$. At higher

22 temperatures, $\mathrm{NCO}$ cathode materials thermally decomposed to $\mathrm{Co}_{3} \mathrm{O}_{4}, \mathrm{CoO}$ and $\mathrm{Co}$ with

23 Co reduction. With higher cut-off voltages, severer Co reduction happens at lower 
1 temperature. In addition, nascent porosity initiates at the edge of particle and propagates

2 into the bulk area. Compared to our previous research on cathode materials for LIBs, ${ }^{12,13}$

3 the charged NCO materials in the present study exhibit similar problems of structural

4 modifications and resultant oxygen loss at high temperatures. As sodium ion batteries are

5 being targeted for large-scale applications, the electrode materials must be thermally

6 stable because both the possibility of failure in heat management and the impact of

7 unwanted heat increase in large units of batteries. Therefore, the P2 type cathode

8 materials should be modified to improve the thermal stability. Methods such as, surface

9 coating, adding and optimizing transition metal compositions into the structure, or

10 controlling the crystal structure are believed to be effective in suppressing the thermal

11 decomposition of $\mathrm{P} 2-\mathrm{Na}_{\mathrm{x}} \mathrm{TMO}_{2}$ materials for sodium ion batteries.

\section{Conclusions}

14 In summary, we used real-time transmission electron microscopy to examine the

15 thermal stability of $\mathrm{P} 2-\mathrm{Na}_{\mathrm{x}} \mathrm{CoO}_{2}$ cathode materials for sodium ion batteries. With

16 increase in the temperature, the surface of $\mathrm{Na}_{\mathrm{x}} \mathrm{CoO}_{2}$ became porous due to the thermal

17 decomposition to $\mathrm{Co}_{3} \mathrm{O}_{4}, \mathrm{CoO}$, and $\mathrm{Co}$ with the reduction of Co. The degree of the

18 thermal decomposition increased at higher cutoff voltages at the same temperature. At the

19 harshest condition of $4.3 \mathrm{~V}$ cutoff voltage and $400{ }^{\circ} \mathrm{C}$ used in this study, significant

20 changes were observed in the morphology as well as the crystallographic and the

21 electronic structures as a result of the reduction of Co to the metallic state and the loss of

22 oxygen, which are serious safety threats to the life of the battery system. This study

23 demonstrates the instability of charged P2-type layered cathode materials at high 
1 temperatures. The thermal stability of electrode materials should be considerably

2 improved in order to guarantee the safe operation of sodium ion batteries, and this work

3 provides an excellent methodology to testify the thermal stability of newly developed

4 cathode materials.

5

6

7 Supporting Information: Further information of atomic absorption spectroscopy result,

8 SAED and EELS analysis

\section{Acknowledgements}

11 This work was supported by the Korea Institute of Science and Technology (KIST)

12 Institutional Program (Project Nos. 2E27062, 2E27090). S.H. acknowledges support to

13 the Center for Functional Nanomaterials, Brookhaven National Laboratory, which is

14 supported by the U.S. Department of Energy, Office of Basic Energy Sciences, under

15 Contract No. DE- SC0012704.

16 


\section{References}

3 (1) Kim, S.-W.; Seo, D.-H.; Ma, X.; Ceder, G.; Kang, K. Electrode Materials for

(2) Yabuuchi, N.; Kubota, K.; Dahbi, M.; Komaba, S. Research Development on

(3) Berthelot, R.; Carlier, D.; Delmas, C. Electrochemical Investigation of the P2$\mathrm{Na}_{\mathrm{x}} \mathrm{CoO}_{2}$ Phase Diagram. Nat. Mater. 2010, 10, 74-80. Yabuuchi, N.; Kajiyama, M.; Iwatate, J.; Nishikawa, H.; Hitomi, S.; Okuyama, R.; Usui, R.; Yamada, Y.; Komaba, S. P2-Type $\mathrm{Na}_{\mathrm{x}}\left[\mathrm{Fe}_{1 / 2} \mathrm{Mn}_{1 / 2}\right] \mathrm{O}_{2}$ Made From 512-517.

Xia, X.; Dahn, J. R. $\mathrm{NaCrO}_{2}$ Is a Fundamentally Safe Positive Electrode Material for Sodium-Ion Batteries with Liquid Electrolytes. Electrochem. Solid-State Lett. 2012, 15, A1-A4.

Ding, J. J.; Zhou, Y. N.; Sun, Q.; Yu, X. Q.; Yang, X. Q.; Fu, Z. W. Electrochemical Properties of P2-Phase $\mathrm{Na}_{0.74} \mathrm{CoO}_{2}$ Compounds as Cathode Material for Rechargeable Sodium-Ion Batteries. Electrochim. Acta 2013, 87, 388-393.

(7) Delmas, C.; Fouassier, C.; Hagenmuller, P. Structural Classification and Properties of the Layered Oxides. Physica $B+C$ 1980, 99, 81-85.

Ong, S. P.; Chevrier, V. L.; Hautier, G.; Jain, A.; Moore, C.; Kim, S.; Ma, X.; Ceder, G. Voltage, Stability and Diffusion Barrier Differences Between SodiumIon and Lithium-Ion Intercalation Materials. Energy Environ. Sci. 2011, 4, 36803688.

(9) Shacklette, L. W.; Jow, T. R.; Townsend, L. Rechargeable Electrodes From Sodium Cobalt Bronzes. J. Electrochem. Soc. 1988, 135, 2669-2674.

(10) Yoon, W.-S.; Balasubramanian, M.; Chung, K. Y.; Yang, X.-Q.; McBreen, J.; Grey, C. P.; Fischer, D. A. Investigation of the Charge Compensation Mechanism on the Electrochemically Li-Ion Deintercalated $\mathrm{Li}_{1 \text { - }}$ 


11)

${ }_{x} \mathrm{Co}_{1 / 3} \mathrm{Ni}_{1 / 3} \mathrm{Mn}_{1 / 3} \mathrm{O}_{2}$ Electrode System by Combination of Soft and Hard X-Ray Absorption Spectroscopy. J. Am. Chem. Soc. 2005, 127, 17479-17487.

Bak, S.-M.; Nam, K.-W.; Chang, W.; Yu, X.; Hu, E.; Hwang, S.; Stach, E. A.; Kim, K.-B.; Chung, K. Y.; Yang, X.-Q. Correlating Structural Changes and Gas Evolution During the Thermal Decomposition of Charged $\mathrm{Li}_{x} \mathrm{Ni}_{0.8} \mathrm{Co}_{0.15} \mathrm{Al}_{0.05} \mathrm{O}_{2}$ Cathode Materials. Chem. Mater. 2013, 25, 337-351. Hwang, S.; Kim, S. M.; Bak, S.-M.; Cho, B.-W.; Chung, K. Y.; Lee, J. Y.; Chang, W.; Stach, E. A. Investigating the Local Degradation and Thermal Stability of Charged Ni-Based Cathode Materials Through Real-Time Electron Microscopy. ACS Appl. Mater. Interfaces 2014, 6, 15140-15147.

(13) Hwang, S.; Kim, S. M.; Bak, S.-M.; Kim, S. Y.; Cho, B.-W.; Chung, K. Y.; Lee, J. Y.; Stach, E. A.; Chang, W. Using Real-Time Electron Microscopy to Explore the Effects of Transition-Metal Composition on the Local Thermal Stability in Charged $\mathrm{Li}_{x} \mathrm{Ni}_{y} \mathrm{Mn}_{\mathrm{z}} \mathrm{Co}_{1-\mathrm{y}-\mathrm{z}} \mathrm{O}_{2}$ Cathode Materials. Chem. Mater. 2015, 27, 39273935.

(14) Xia, X.; Dahn, J. R. A Study of the Reactivity of De-Intercalated P2- $\mathrm{Na}_{x} \mathrm{CoO}_{2}$ with Non-Aqueous Solvent and Electrolyte by Accelerating Rate Calorimetry. $J$. Electrochem. Soc. 2012, 159, A647-A650.

(15) Zhao, J.; Zhao, L.; Dimov, N.; Okada, S.; Nishida, T. Electrochemical and Thermal Properties of a- $\mathrm{NaFeO}_{2}$ Cathode for Na-Ion Batteries. J. Electrochem. Soc. 2013, 160, A3077-A3081.

(16) Yu, C.-Y.; Park, J.-S.; Jung, H.-G.; Chung, K. Y.; Aurbach, D.; Sun, Y.-K.; Myung, S.-T. $\mathrm{NaCrO}_{2}$ Cathode for High-Rate Sodium-Ion Batteries. Energy Environ. Sci. 2015, 8, 2019-2026.

(17) Grey, C. P.; Tarascon, J.-M. Sustainability and in Situ Monitoring in Battery Development. Nat. Mater. 2017, 16, 45-56.

(18) Hwang, S.; Chang, W.; Kim, S. M.; Su, D.; Kim, D. H.; Lee, J. Y.; Chung, K. Y.; Stach, E. A. Investigation of Changes in the Surface Structure of $\mathrm{Li}_{\mathrm{x}} \mathrm{Ni}_{0.8} \mathrm{Co}_{0.15} \mathrm{Al}_{0.05} \mathrm{O}_{2}$ Cathode Materials Induced by the Initial Charge. Chem. Mater. 2014, 26, 1084-1092.

(19) Yang, H. X.; Nie, C. J.; Shi, Y. G.; Yu, H. C.; Ding, S.; Liu, Y. L.; Wu, D.; 
Wang, N. L.; Li, J. Q. Structural Phase Transitions and Sodium Ordering in $\mathrm{Na}_{0.5} \mathrm{CoO}_{2}$ : a Combined Electron Diffraction and Raman Spectroscopy Study. Solid State Commun. 2005, 134, 403-408.

4 (20) Keast, V.; Scott, A. J.; Brydson, R.; Williams, D. B.; Bruley, J. Electron EnergyLoss Near-Edge Structure-a Tool for the Investigation of Electronic Structure on

(21) Graetz, J.; Ahn, C. C.; Ouyang, H.; Rez, P.; Fultz, B. White Lines and D-Band Occupancy for the 3d Transition-Metal Oxides and Lithium Transition-Metal Oxides. Phys. Rev. B 2004, 69, 235103.

10 (22) Zhao, Y.; Feltes, T. E.; Regalbuto, J. R.; Meyer, R. J.; Klie, R. F. In Situ Electron Energy Loss Spectroscopy Study of Metallic Co and Co Oxides. J. Appl. Phys. 2010, 108, 063704.

13

14 


\section{Figures}

2
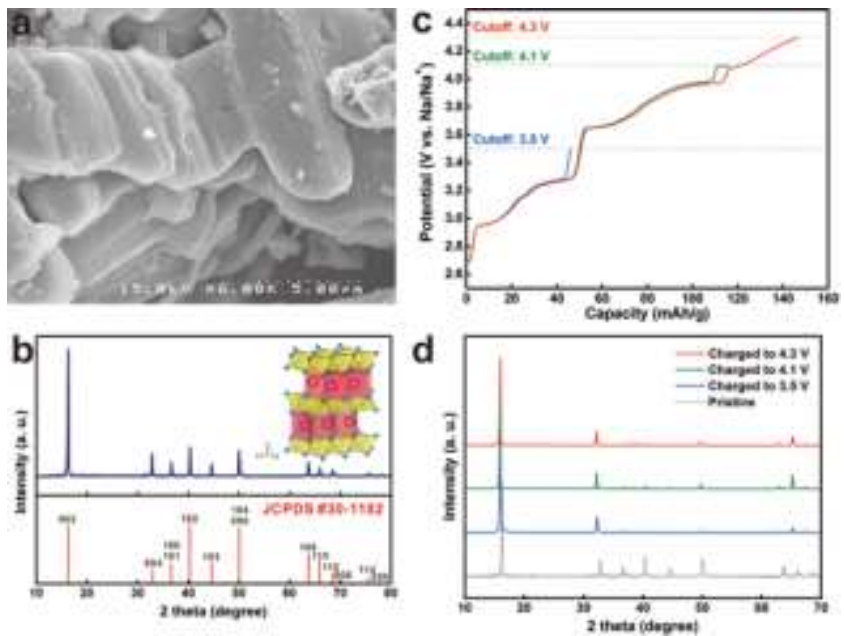

Figure 1. (a) SEM image and (b) X-ray diffraction pattern of as-synthesized NCO 5 cathode material. (c) Charge profiles of $\mathrm{NCO}$ cathode matrials with cut-off voltages of $63.5,4.1$, and $4.3 \mathrm{~V}$. (d) X-ray diffraction patterns of $\mathrm{NCO}$ cathode materials before and 7 after initial charge.

8
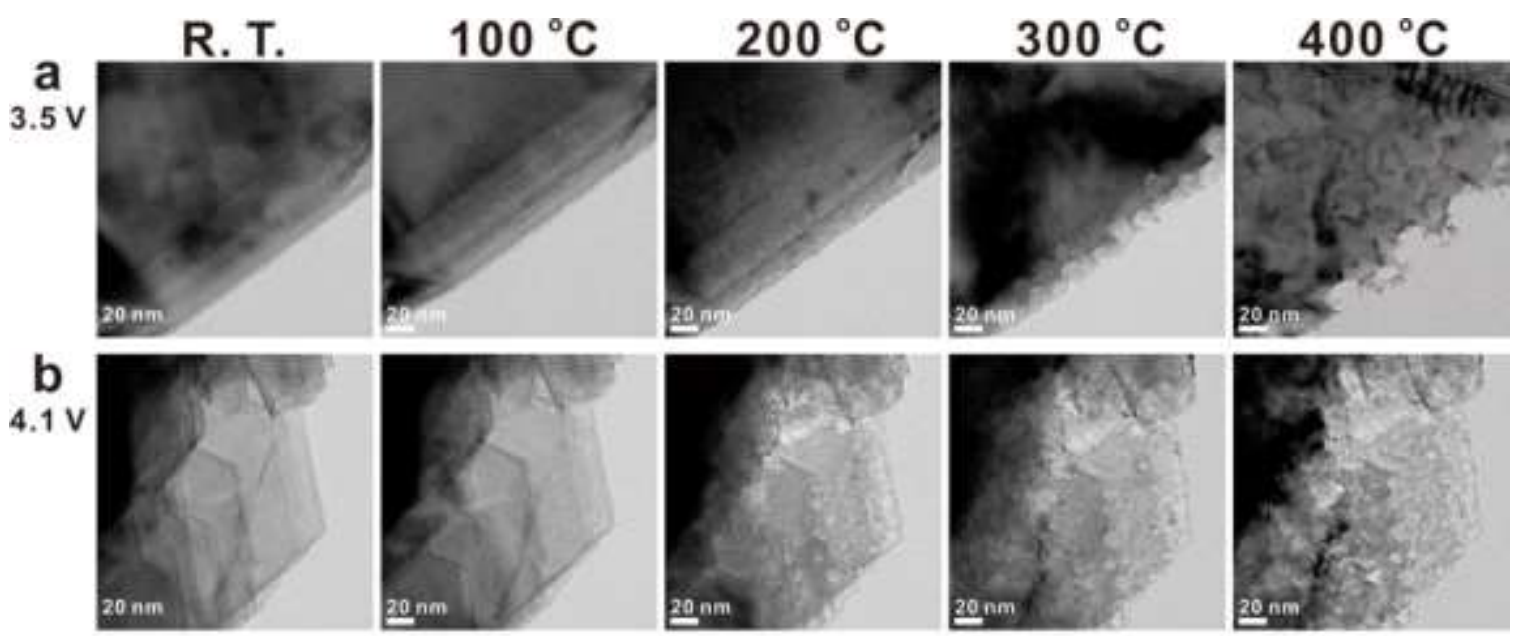

C.3 V
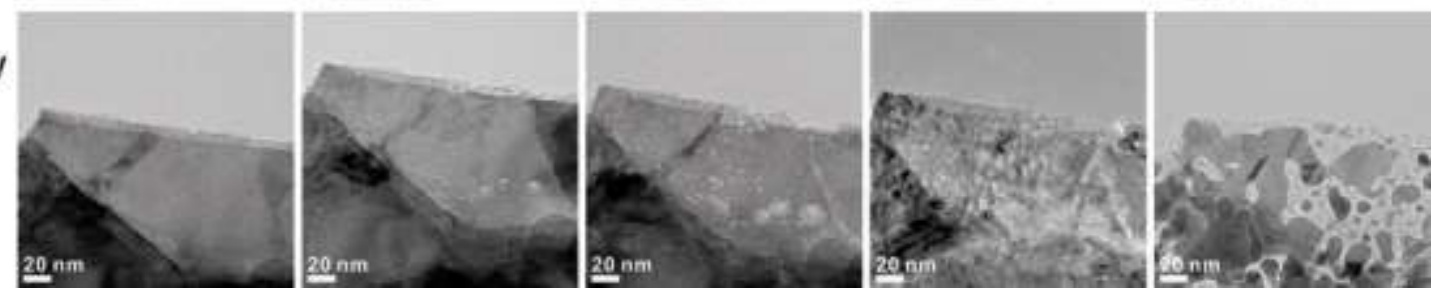

10 Figure 2. Real-time BF images of the surface of NCO cathode materials charged to (a)

$113.5 \mathrm{~V}$, (b) $4.1 \mathrm{~V}$, and (c) $4.3 \mathrm{~V}$ during heating.

12 


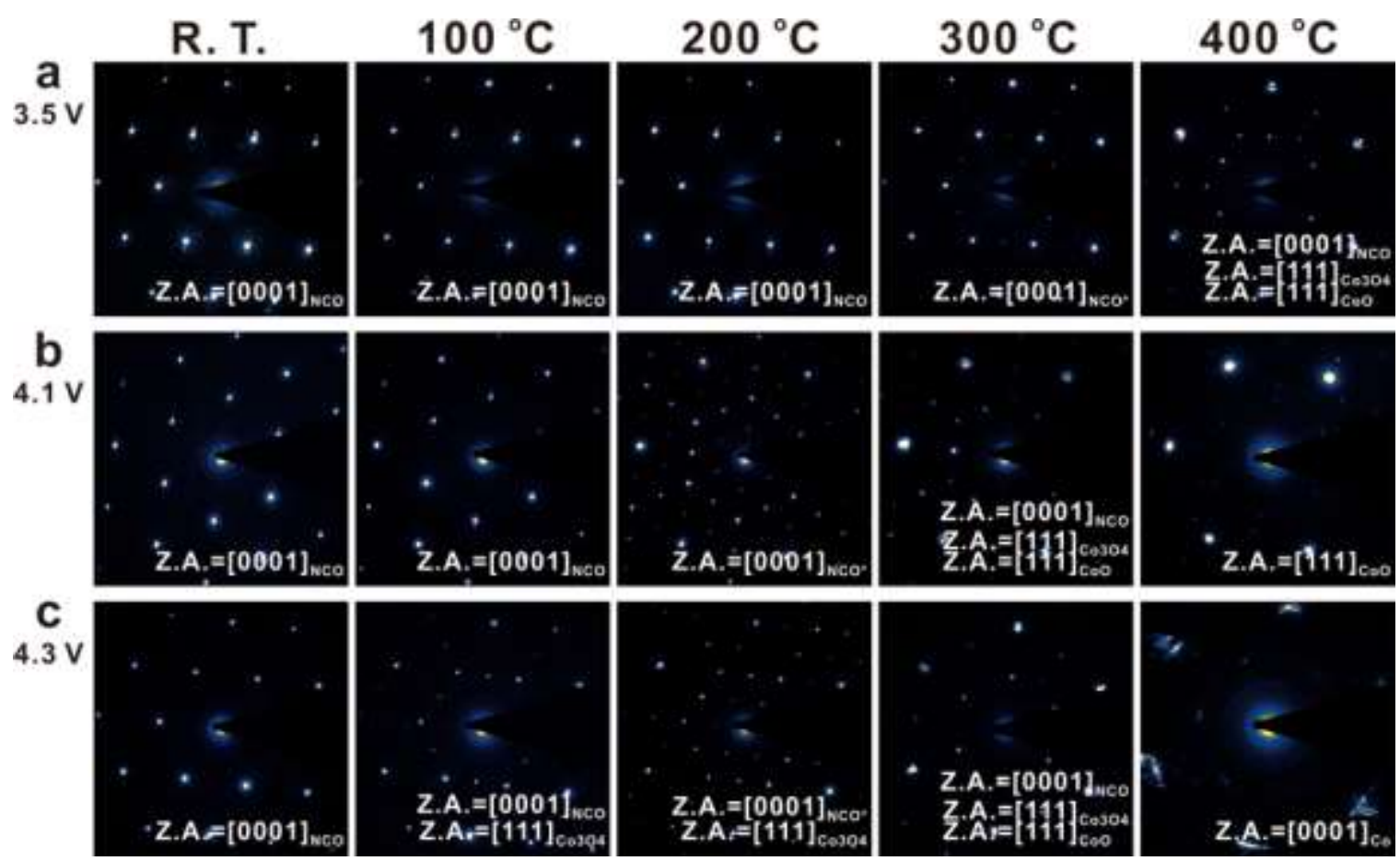

2 Figure 3. Real-time electron diffraction patterns acquired from the surface of NCO 3 cathode materials charged to (a) $3.5 \mathrm{~V}$, (b) $4.1 \mathrm{~V}$, and (c) $4.3 \mathrm{~V}$ during heating. NCO* 4 exhibits that NCO phase with sodium ordering.
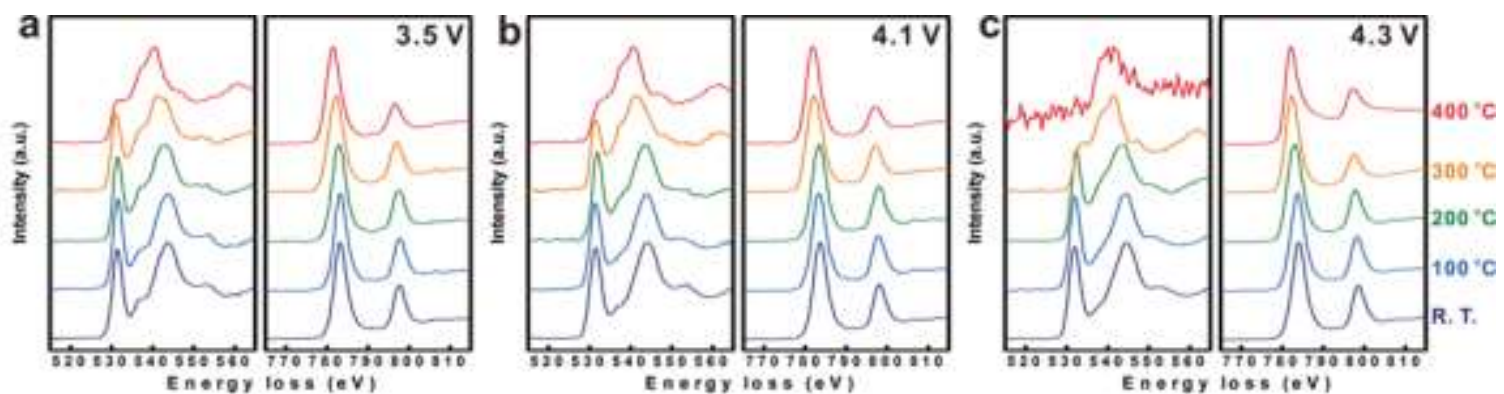

7 Figure 4. $\mathrm{O}$ K-edge and $\mathrm{Co}_{2,3}$ edge EEL spectra of $\mathrm{NCO}$ cathode materials charged to (a) $3.5 \mathrm{~V}$, (b) $4.1 \mathrm{~V}$, and (c) $4.3 \mathrm{~V}$ during heating. 

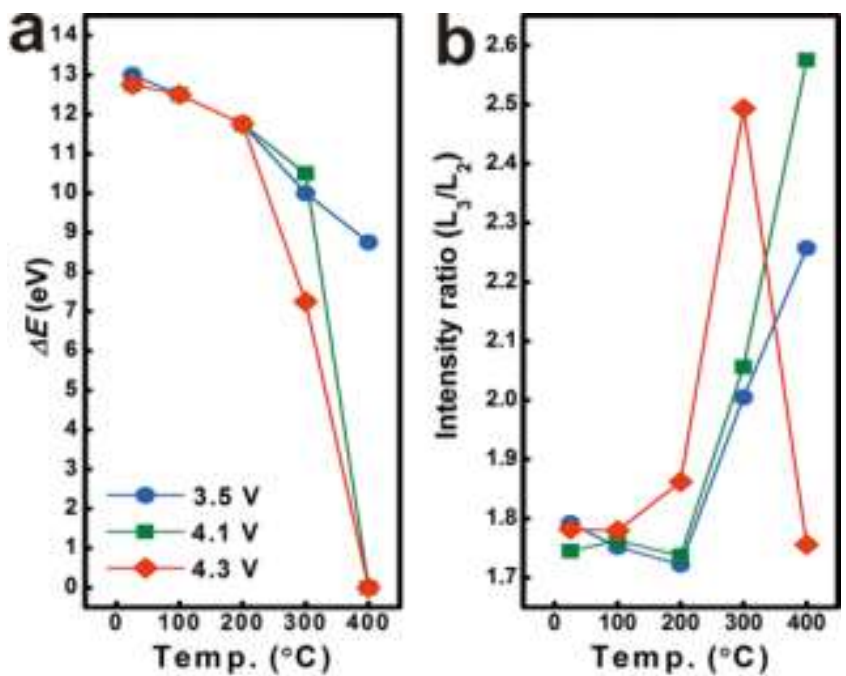

2 Figure 5. Changes in (a) $\Delta \mathrm{E}$ of $\mathrm{O}$ K-edge and (b) $\mathrm{L}_{3} / \mathrm{L}_{2}$ intensity ratio of Co L edge with

3 increasing temperature

4

5

6

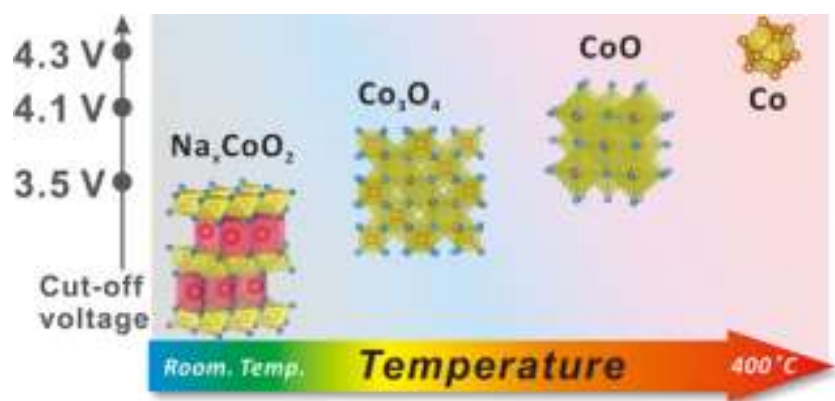

7 Figure 6. A scheme that summarizes thermal decomposition of charged NCO 